\title{
Unlocking towns and cities: COVID-19 exit strategy
}

Salman Rawaf, ${ }^{1}$ Harumi Quezada Yamamoto ${ }^{2}$ and David Rawaf ${ }^{3}$

${ }^{2}$ Director of WHO Collaborating Centre, Imperial College London, London, United Kingdom. ${ }^{2}$ Department of Primary Care and Public Health, Imperial College London, London, United Kingdom. ${ }^{3}$ Epsom and St Helier Hospitals NHS Foundation Trust and Researcher, Imperial College London, London, United Kingdom. (Correspondence to: s.rawaf@imperial.ac.uk; whocentre@imperial.ac.uk).

Citation: Rawaf S; Quezada Yamamoto H; Rawaf D. Unlocking towns and cities: COVID-19 exit strategy. East Mediterr Health J. 2020;26(5):499-502. https://doi.org/10.26719/emhj.20.028

Received: 26/04/20; accepted: 03/05/20

Copyright (c) World Health Organization (WHO) 2020. Open Access. Some rights reserved. This work is available under the CC BY-NC-SA 3.0 IGO license (https://creativecommons.org/licenses/by-nc-sa/3.o/igo).

\section{Introduction}

The novel Coronavirus SARS-2 represents a major global challenge since the first cases were diagnosed in China and reported to the World Health Organization (WHO) on 31 December 2019 (1). On 9 January 2020, WHO issued a statement warning of the 'risk' of human-to-human transmission, although China did not report such a method of transmission (2). WHO officially declared a Public Health Emergency on 30 January 2020 and the disease was named COVID-19 on 11 February 2020. On 11 March, it was characterized as a pandemic when the number of cases increased 13-fold. At this point, it had spread to over 60 countries across all continents except Antarctica, with an immediate and profound effect on societies and brought social and economic life to a virtual standstill. As of 30 April, 2020, 3271892 cases of COVID-19 were reported globally with 232817 deaths (3). More than one-third of the world population was locked down (4), as part of the 'suppression' strategy first proposed by Imperial College London, United Kingdom (5). Such a strategy is aimed at reducing the spread of infection, protect health services and save lives. However, it has a major economic impact globally and has had a deep social and psychological impact on many people. Therefore, it is not feasible to maintain the current lockdown indefinitely. This commentary aims to define the public health principles and the measures that must be considered for a science-based political decision to unlock towns and cities.

\section{Unlocking towns and cities}

At any stage of the pandemic, political decisions must be built upon a mixture of scientific evidence of the outbreak control and political imperative to ensure economic continuity. The fear of a second wave must always be uppermost in the mind of decision-makers and the country should have a clear plan and preparation for such an eventuality. Indeed, the director of the Centers for Disease Control and Prevention, United States, warned that a second wave of COVID-19 is inevitable, and it is 'likely to be more devastating' (6). Any decision on unlocking towns and cities should consider a range of existing and emerging evidence so far.
We know that the world is facing a new virus and a new dynamic. Novel evidence is emerging day-by-day as we learn how to tackle the virus effectively (7). Still, many gaps in our knowledge do exist. These include the absence of a vaccine, despite major efforts both publicly and commercially, and no definitive treatment despite the use of antimalarial drugs, antibiotics, antiviral medication, anticoagulants, Interleukin (IL-6) inhibitors, blood transfusions and plasma treatment $(7,8)$. Furthermore, little evidence of full immunity is available (9) and reinfection is reported (10). Some countries are assessing the level of immunity through antibodies' tests (11), yet emerging studies demonstrate that there is more than one genotype of COVID-19 virus (SARS-CoV-2) with different infectivity level, spread and immunity (12). In the absence of a vaccine or treatment, modelling suggests that it can take nine waves of infection to achieve herd immunity (13).

While science is progressing, the mill of misinformation or "fake news", is fed by some scientists reporting non-evidence-based experiences and opinions, and public "fear" is at its highest. This is aggravated by some politicians who are happy to trigger blame and even agitate populations for action against national and local lockdown rules, mainly to score political points (14). Others have criticised the strict public health measures and advocated for more liberal approaches to achieve herd immunity. However, such policies proved less effective than initially thought and restrictive public health measures were gradually introduced (15). The current coronavirus is not like seasonal influenza and the next wave, if any, will be during any season. Even though this has yet to be proven, we must remember that seasonality does not constrain new viruses in the same way that long-existing viruses are affected (16). Although $81 \%$ of the COVID-19 cases are either subclinical or mild, the lack of credible treatment to deal with moderate and severe cases (17) and the absence of a vaccine to achieve full herd immunity, may lead some countries to endure repeated waves of infection (6). Overall, we are aware that our social life and economy are suffering, jobs are lost, families are separated, and mental health is at risk (18). Any analysis or risk assessment for unlocking should 
be framed within public health principles outlined as follows, and consider the above scientific evidence, or lack of it.

\section{Public health principles for unlocking towns and cities}

Governments cannot continue locking down towns and cities forever. A clear and explicit "exit strategy" to unlock and restore "normality" is needed for each country with emphasis on key public health principles and indicators unique to the population. Each government, based on these principles, must decide how long the lockdown and social distancing should continue, what should be eased, the stages of easing such a lockdown and measures taken to monitor the abatement of the virus. Most countries need to develop a collaborative stepwise approach and prepare for the transition to ease the shutdown, especially those with shared borders or land mass. Four important principles should be carefully analysed and calibrated. Relaxed measures should be a holistic approach incorporating all the four public health principles rather than the decline of infection. These principles are; infection status; community acceptance; public health capacity; and health system spare capacity.

\section{The Infection Status}

Key indicators should be considered. We suggest the use of the following if effective measurements are available, based on epidemic thresholds and techniques for analysis of infectious disease data (construction and use of epidemic curves, generation number, exception reporting, identification of significant clusters).

First, the rate of infection, expressed as an incidence rate. This is the number of new cases within a time period, as a proportion of the number of people at risk. A declining incidence rate is evidence that the virus transmission has slowed down, i.e., the infection curve is flattening and the basic reproduction number (Ro) is below 1 . Second, the doubling rate of infection, referring to the number of days needed to double the number of infected people. Increase in doubling time indicates a slowdown in transmission (if underlying reporting remains unchanged). A doubling rate between two weeks and one month, or longer, could allow for easing restriction. Third, case contacts, ideally expecting the number of contacts generated per case to be one or less. Fourth, testing positivity rate as the proportion of all samples testing positive; this should be no more than $5 \%$.

Different methods can be used to monitor the infection status. Smartphone applications could track, trace and follow-up contacts, mild symptomatic cases and positive cases with no symptoms (19). Data must be accurate, timely and thus there will be heavy reliance and trust in official communication streams regarding numbers.

\section{Community acceptance}

Unlocking, partially or completely, is a political decision based on clear and specific public health advice at the highest level in government. The measures that need to be taken may continue to affect communities' economy and lifestyle in the short and long term. Therefore, to ensure full public engagement, it is vital that governments are transparent and include community acceptance in the equation. This is a complex issue and the "new normal" means adjusting work, social, and economic activities, which may not be fully resumed until an effective treatment and / or a vaccine are available.

Some elements of social distancing should continue. These range from prohibiting gatherings (social, religious, conferences, large sport events, cinemas, gyms, theatres etc.); limiting movement of people between towns and cities depending on the subnational analysis of the rates of infection; to continuation of shielding people over the age of 70 years old, vulnerable children and those at high risk (e.g. immune-compromised) until further notice. Avoidance of customary greetings such as handshakes and kissing as well as concurrent vigorous hand washing advice will be the norm for some time to come. Travel on public transport and commercial aircraft will be redesigned to maintain social distancing through seat spacing and passengers number restrictions. Shopping and other social activities should follow strict rules on social distances and protect workers in the service industry. The gradual reopening of schools in phases, starting with pupils up to the age of 11 years old, may be feasible following Denmark's example (20).

Student learning and examinations, including those of medical schools, should seek to continue to comply with social distancing measures. Economically, the population must accept new or increases in taxation for a period to forfeit the dire economic situation created by COVID19's lockdown. Furthermore, certain employees, public and private, may need to accept "reasonable" reductions in incomes and reduced benefits. These indicators must be assessed fully regarding public engagement and acceptance. At the same time, immediate measures must be introduced to prevent worsening poverty and to alleviate any suffering caused by COVID-19.

\section{Public health capacity and measures}

Public health capacity draws not only on resources but also on organizational structures, partnerships, leadership and governance in the country specific context. So far in this pandemic, strict public health measures are showing to be effective (21). This response has required recruitment at short notice to bridge gaps in the workforce. Therefore, it is vital that public health capacity is given the full support required in terms of workforce, laboratories, transport, medical equipment, personal protective equipment, settings and other logistics. National and local governments should provide sufficient legal power for public health agencies at national and local level to take further actions as deemed necessary. Data collection, analysis, modelling, projections and reporting should be given full priority in collaboration with academia and international organisations such as WHO and the United Nations Children's Fund (UNICEF). 
Surveillance is a vital part of public health functions. Public health agencies nationally and locally should have in place highly effective surveillance systems in a variety of settings to assess current infections and predict any possible new wave(s) of infections, thereby triggering the correct measures for suppressing it (being ahead of the curve). Such surveillance should include a welldefined system of active case finding, testing, isolation of positive cases, tracking all immediate contacts, and ensuring quarantine accommodation is decent and under continuous surveillance. All ports of entry should also be subjected to such a system.

Public health agencies, at national and local level, should provide adequate, transparent and timely public information, which should be in all languages used by the communities. It has been reported, for example in Sweden, that the numbers of COVID-19 cases were much higher among immigrants, who represent about $25 \%$ of the total population (15). Last but not least, the emergency preparedness plan must be updated on a regular basis taking into account the speed of development in this pandemic. Such updated plans must be shared with all sections of government, which should ensure that indicators of public health capacity are at the appropriate level before considering relaxing lockdown measures.

\section{Health system spare capacity}

Protecting the health system to ensure that it will not be overwhelmed is one of the major public health challenges during this pandemic. Except for a few countries, most health systems around the world were not prepared for this pandemic (21). This was reflected in weak public health infrastructure, shortages in intensive care beds, shortage of equipment (oxygen supply, ventilators, personal protective equipment, transport, morgues, etc.), and shortages of staff. In reality, most health systems were operating at near $99 \%$ capacity before the pandemic. Therefore, in preparation for the partial or complete "unlock", the entire health system must be ready. Singapore, Taiwan and South Korea have learnt the lesson of SARS- 1 and MERS in the last two decades and prepared their health systems for such eventualities (21). These countries invested in their health systems for the future to save lives and reduce the economic cost in the event of a pandemic repeat. Other countries should do the same.

Some of the vital measures that must be taken in preparation for another spike if lockdown is partially or completely removed include hospitals having spare capacity of at least $20 \%$, especially in intensive care (22). Germany has less deaths due to COVID-19 compared with other European countries mainly due to the huge spare bed capacity including intensive care (22). However, not all hospitals should receive COVID-19 patients. If another wave appears after a partial or complete unlock, hospitals receiving COVID-19 patients should be redesigned with clear infection and prevention control procedures; e.g., red areas with restricted access, amber areas for recovered patients and green for normal hospital activities. Such measures protect staff, reduce cross infection and save lives. Staff should be trained to move to other duties (redeployment) to respond to another wave, e.g., higher needs in intensive care units.

Intensive care training should be mandatory for all medical and nursing students. Primary care should be structured to deliver more effective services to suspected cases and contacts, as well as continue to provide the vital health care services as the first point of contact within the health system while maintaining high level of continuity of care. Patients discharged from intensive care require follow-up and primary care should be well positioned to do so. Ambulance services should be enhanced, both in number and training, to provide a wide range of COVID-19 care from immediate intervention at home and support during transportation, to setting patients at home with oxygen therapy. Finally, volunteer services and community groups should be structured and organised to avoid any future confusion.

All these measures should be part and parcel of the country or local emergency preparedness plans, which must be robust, evidence-based and ensure community engagement. We must be vigilant through surveillance, monitoring and risk assessment and it must be clear to the public that, if the trend shows an increase in the number of new cases, a quick re-introduction of physical distancing measures to contain the virus will be required.

\section{Conclusions}

While some countries are reporting a decline in new COVID-19 cases, many others are yet to feel the full impact of the virus. Maintaining current aggressive social distancing measures until an effective treatment or vaccine are available, is not practical. Gradually relaxing restrictions when infection indicators (decreased transmission and spread of the virus) and other conditions are met, could help further easing of measures until the authorities are sure that no new cases are reported for a reasonable length of time. Governments must ensure that their unlocking plan can be implemented in practice, clearly communicated and enforced. The psychological, social and economic impacts of COVID-19 on individuals, communities and businesses are immediate, profound and with long-term consequences. Humanity is in a challenging scenario with this novel coronavirus and the only road we should take is to fight together and to fight smart. 


\section{References}

1. World Health Organization. Pneumonia of unknown cause - China. Geneva: World Health Organization; 5 January 2020 (https:// www.who.int/csr/don/05-january-2020-pneumonia-of-unkown-cause-china/en/, accessed 27 April 2020).

2. World Health Organization. WHO statement regarding cluster of pneumonia cases in Wuhan, China. Geneva: World Health Organization; 9 January 2020 Available at: https://www.who.int/china/news/detail/09-01-2020-who-statement-regarding-cluster-of-pneumonia-cases-in-wuhan-china, accessed 19 April 2020).

3. Coronavirus Resource Center. Johns Hopkins University. (https://coronavirus.jhu.edu, accessed 19 April 2020).

4. Buchholz K. What share of the world population is already on COVID-19 Lockdown? Statista (https://www.statista.com/ chart/21240/enforced-covid-19-lockdowns-by-people-affected-per-country/, accessed 23 April 2020).

5. Walker P, Whittaker C, Watson O, Baguelin M, Ainslie KEC, Bhatia S, et al. Report 12- The global impact of COVID 19 and strategies for mitigation and suppression. London: Imperial College London; 26 March 2020 (https://www.imperial.ac.uk/mrc-global-infectious-disease-analysis/covid-19/report-12-global-impact-covid-19/, accessed 19 April 2020).

6. Sun LH. CDC director warns second wave of coronavirus is likely to be even more devastating. Washington Post. (https://www. washingtonpost.com/health/2020/04/21/coronavirus-secondwave-cdcdirector/, accessed 21 April 2020).

7. Del Rio C, Malani PN. COVID-19-New insights on a rapidly changing epidemic. JAMA. 2020;323(14):1339-1340. doi:10.1001/ jama.2020.3072

8. Lovelace B, Feuer W. WHO warning: no evidence that antibody tests can show coronavirus immunity. CNBC. (https://www. cnbc.com/2020/04/17/who-issues-warning-on-coronavirus-testing-theres-no-evidence-antibody-tests-show-immunity.html, accessed 19 April 2020).

9. Hancocks P, Seo Y, Hollingsworth J. Recovered coronavirus patients are testing positive again. Can you get reinfected? CNN. (https://edition.cnn.com/2020/04/17/health/south-korea-coronavirus-retesting-positive-intl-hnk/index.html, accessed 19 April 2020).

10. Ota M. Will we see protection or reinfection in COVID-19? Nat Rev Immunol. 2020. https://doi.org/10.1038/s41577-020-0316-3

11. Armstrong M. Germany starts mass-testing for coronavirus antibodies in bid to learn more about COVID-19. Euronews (https:// www.euronews.com/2020/04/19/germany-starts-mass-testing-for-coronavirus-antibodies-in-bid-to-learn-more-about-covid-19, accessed 21 April 2020).

12. Changchuan Y. Genotyping coronavirus SARS-CoV-2: methods and implications [pre-print] (https://arxiv.org/pdf/2003.10965. pdf, accessed 19 April 2020).

13. Cullen P. Coronavirus: Herd immunity may take multiple waves of infection - study. Irish Times. (https://www.irishtimes.com/ news/health/coronavirus-herd-immunity-may-take-multiple-waves-of-infection-study-1.4232873, accessed 19 April 2020).

14. Coronavirus: US held funding from WHO. BBC Online. (https://www.bbc.co.uk/news/world-us-canada-52289056, accessed 22 April 2020).

15. Bergstrom H. The grim truth about the "Swedish Model". Project Syndicate. (https://www.project-syndicate.org/commentary/ swedish-coronavirus-no-lockdown-model-proves-lethal-by-hans-bergstrom-2020-04, accessed 19 April 2020).

16. Lipsitch M. Seasonality of SARS-CoV-2: Will COVID-19 go away on its own in warmer weather? Center for Communicable Disease Dynamics, Harvard University (https://ccdd.hsph.harvard.edu/will-covid-19-go-away-on-its-own-in-warmer-weather/, accessed 19 April 2020).

17. Wu Z, McGoogan JM. Characteristics of and important lessons from the coronavirus disease 2019 (COVID-19) outbreak in China: summary of a report of 72314 cases from the Chinese Center for Disease Control and Prevention. JAMA. 2020;323(13):1239-1242. doi:10.1001/jama.2020.2648

18. Kennedy S. Risk to jobs unprecedented since the great depression. Bloomberg. (https://www.bloomberg.com/news/articles/2020-04-03/jobs-destroyed-worldwide-as-coronavirus-sparks-recession, accessed 22 April 2020).

19. Kasulis K. S Korea's smartphone apps tracking coronavirus won't stop buzzing. Aljazeera Online. (https://www.aljazeera.com/ news/2020/04/korea-smartphone-apps-tracking-coronavirus-won-stop-buzzing-200408074008185.html, 22 April 2020).

20. Gargiulo S. Denmark's return to school gives glimpse of what classrooms will look like post-lockdown. CNN Online (https://edition.cnn.com/2020/04/17/europe/denmark-coronavirus-first-school-intl/index.html, accessed 19 April 2020).

21. Cheung H. Coronavirus: what could the West learn from Asia. BBC Online. (https://www.bbc.co.uk/news/world-asia-51970379, accessed 19 April 2020).

22. Chazan Guy. Oversupply of hospital beds helps Germany to fight virus. Financial Times Online. (https://www.ft.com/content/ d979coe9-4806-4852-a49a-bbffagcecfe6, Accessed 19th April 2020). 